
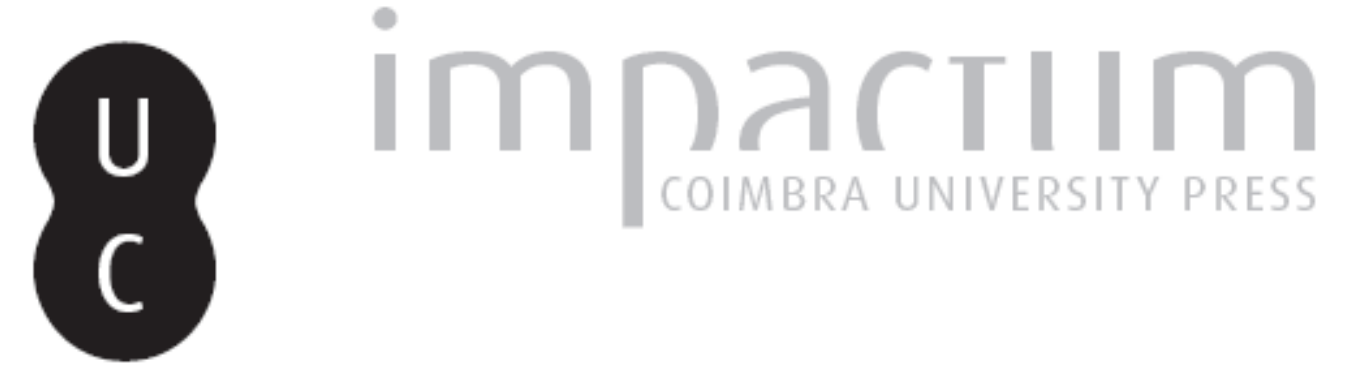

\title{
El jansenismo en España y su caracter de ideologia revolucionaria
}

Autor(es): $\quad$ Alvarez de Morales, Antonio

Publicado por: Imprensa da Universidade de Coimbra

URL persistente:

URI:http://hdl.handle.net/10316.2/43779

DOI:

DOI:https://doi.org/10.14195/2183-8925_10_20

Accessed : $\quad$ 26-Apr-2023 11:44:09

A navegação consulta e descarregamento dos títulos inseridos nas Bibliotecas Digitais UC Digitalis, UC Pombalina e UC Impactum, pressupõem a aceitação plena e sem reservas dos Termos e Condições de Uso destas Bibliotecas Digitais, disponíveis em https://digitalis.uc.pt/pt-pt/termos.

Conforme exposto nos referidos Termos e Condições de Uso, o descarregamento de títulos de acesso restrito requer uma licença válida de autorização devendo o utilizador aceder ao(s) documento(s) a partir de um endereço de IP da instituição detentora da supramencionada licença.

Ao utilizador é apenas permitido o descarregamento para uso pessoal, pelo que o emprego do(s) título(s) descarregado(s) para outro fim, designadamente comercial, carece de autorização do respetivo autor ou editor da obra.

Na medida em que todas as obras da UC Digitalis se encontram protegidas pelo Código do Direito de Autor e Direitos Conexos e demais legislação aplicável, toda a cópia, parcial ou total, deste documento, nos casos em que é legalmente admitida, deverá conter ou fazer-se acompanhar por este aviso.

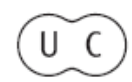


REVISTA DE HISTORIA DAS IDEIAS IO
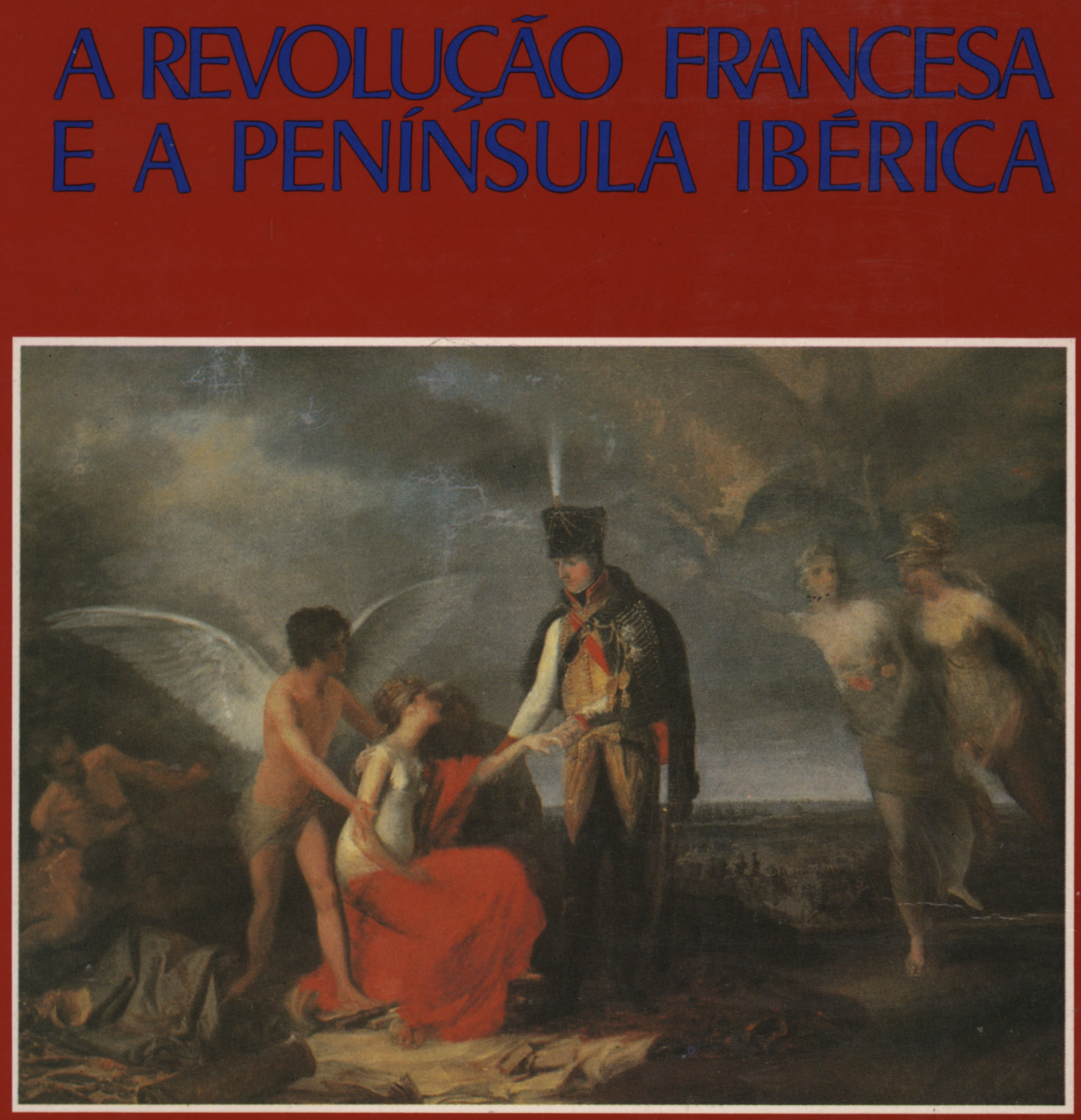

INSTITUTO DE HISTÖRIA E TEORIA DAS IDEIAS FACULDADE DE LETRAS 
ANTONIO ALVAREZ DE MORALES *

\section{EL JANSENISMO EN ESPAÑA Y SU CARACTER DE IDEOLOGIA REVOLUCIONARIA}

\section{Introdución}

Observamos hoy a nuestro alrededor el éxito de la «teología política», como nacida del Concilio Vaticano II, relacionada con una filosofía de la ruptura, necesaria para una doble liberación, interna en el seno de la sociedad eclesial, externa en tanto que los cristianos quieren promover la Iglesia como institución de justicia y verla como movimiento profético contra todas las presiones políticas y económicas.

Pero estos análisis ignoran el pasado, como si la historia del Occidente cristiano hubiese ignorado la noción de «teología política». De este termino mixto, unas veces se ha exaltado el primer termino, y lo político fue sometido al imperialismo teológico, y otras veces, la insistencia se puso en el adjetivo y la teología se convirtió en política eclesiástica. Entre estos dos extremos, ha habido numerosos tipos de situación. Es decir, que un estudio científico de las diversas teologías políticas que han podido sucederse o, incluso, coexistir ilustran la historia de las naciones europeas.

Es de sumo interés abordar el tema del jansenismo precisamente en este periodo histórico que va desde fines del siglo XVIII a la Restauración de las Monarquías Absolutas, mas allá por tanto de la crisis revolucionaria ya que esta generación jansenista se vió confrontada con cambios excepcionales, lo que no le ocurrió las anteriores, y sobre todo pone de manifiesto la enorme contradicción en que llegado a este momento histórico se mueven los jansenistas. Son a la vez la punta de lanza de una Iglesia revolucionaria y los defensores de una

* Universidad Autónoma de Madrid. 
extrema rigidez en materia teológica que rechazaba toda antropolgía nueva.

Esta contradicción es la raíz en mi opinión de las diferencias notables que se advierten dentro de este jansenismo que no se identifica con una imagen habitual que ha dado la historiografía de un reformismo uniforme. Además esta historiografía ha cometido otro error importante, emplear conceptos teológicos contemporáneos para referirse al pasado, es evidente por ejemplo que los jansenistas no tenían, no podían tener una teoría de la secularización. Trato pues de aproximarme al tema desde otro punto de vista que creo mas riguroso y sobre todo mas convincente para entender el jansenismo en España a finales del siglo XVIII y primeros de XIX.

\section{El jansenismo español en el siglo XVIII}

Con respecto al jansenismo del siglo XVIII en España, hay que decir que el termino como en otros países católicos fué introducido por los jesuitas para desembarazarse de sus enemigos eclesiásticos: agustinos, dominicos, etc. La expulsión de aquéllos situó el problema de otra forma y alguns historiadores se han dedicado a tratar de establecer si en España se puede hablar de un jansenismo como en Francia o mas bien fué un termina que se siguió utilizando con fines polémicos.

La obsesión de estos historiadores por demostrar la influencia francesa durante esta época, el caso mas significativo es el de Sarrailh, les ha llevado a afirmar que sí se puede hablar de un verdadero jansenismo en España, naturalmente dependiente del francés (1). Pero creo que esto no es así. Parece claro que los testimonios de la época no reflejan ni mucho menos esto. Cuando por ejemplo Jovellanos se refiere al partido jansenista, me parece que no hay duda que esta empleado el termino con un caracter político.

Señalar como hace Appolis la creación de la cátedra de Lugares Teológicos en un Seminario, el nombramiento de Llorente como secretario de la Inquisición, o de identificación de Jovellanos como jansenista como testimonio de jansenismo es erróneo $\left(^{2}\right)$. Si este autor conociera mejor la historia de España

\footnotetext{
(1) J. Sarrailh, La España ilustrada de la segunda mitad del siglo XVIII, México, 1957.

(2) Emile Appolis, Les jansenistas espagnoles, Sobodi, Bordeaux 1966. Mas acertados son los trabaios de: M. Giovanna Tomsich, El jansenismo en España. Estudio sobre ideas religiosas en la segunda mitad del siglo XVIII, Madrid, 1972; Joël Saugnieux, Le jansenisme
} 
de la segunda mitad del siglo XVIII y especialmente la historia de la reforma universitaria vería como la creación de cátedras de Lugares Teológicos en las que se introduce como libro de texto la obra del teólogo dominico del siglo XVI Melchor Cano se inscribe en otro contexto que el jansenista, no digamos nada de la referencia a Llorente que lo mismo fué jansenista que godoista que afrancesado. Sobre Jovellanos se han escrito ríos de tinta sobre su pensamiento y desde luego no parece que se le pueda calificar de jansenista.

Por eso es un lugar comun señalar que cuando nos referimos al jansenismo en el siglo XVIII no se trata del jansenismo original planteado por Jansenio en su doctrina de la gracia. Dejado de lado este, hay otro jansenismo que es el que envuelve la ideología de los enemigos de los jesuítas y que se colocaron por ello enfrente de estos defendiendo una forma de espiritualidad que se oponía a la de aquellos y que se reflejaba sobre todo en el terreno de la moral, en donde frente a la moral laxa de los jesuítas defienden ellos una moral rígida ${ }^{(3)}$. A ello se juntan algunos otros aspectos siempre presentes en la Historia de la Iglesia como el episcopalismo y el conciliarismo que pretenden basarse en una vuelta a los verdaderos orígenes del cristianismo tal como se practicaba en los primeros siglos.

Así en el reinado de Carlos IV había claramente un partido jansenista con una connotación claramente política, aunque poco precisa, porque en definitiva y sobre todo a partir del ascenso al poder de Godoy, este llamado partido jansenista viene a engrosar la larga lista de los que se oponen al nuevo primer ministro $\left({ }^{4}\right)$. La actividad del grupo jansenista que gira

espagnol du XVIII siècle, ses composants et ses sources, Universidad de Oviedo, 1976; Joël Saugnieux, La ilustración Católica en España. Escritos de don Antonio Tavira Obispo de Salamanca (1737-1807), Salamanca - Oviedo, 1986.

(3) El agustino Miguelez a finales del siglo pasado publicó un libro en el que trató de defender a su orden religiosa de la tacha de jansenista lanzada contra ella por los jesuítas. Ya en aquel momento los agustinos sintieron la necesidad, como es natural, de defenderse de esta acusación y a ello responde sobre todo la contestación del Padre Rojas titulada "El pájaro en la liga» a la obra del Abate Bonola, Liga de la Teología moderna con la filosofía en daño de la Iglesia de Jesucristo, en la que se defendía el molinismo a capa y espada. En efecto no parece que los agustinos españoles constituyeran ni en este ni en otro momento un foco jansenista, Jansenismo y Regalismo en España, Valladolid, 1895.

(4) Jovellanos escribe en su Diario «Decreto para admitir la bula Auctorem fidei. Orden para su observancia. Azotes al partido llamado jansenista. !Ah !Quien se los dá Dios mio! pero ya habrá venganza». 
alrededor de la condesa de Benavente hay que entenderla como una faceta mas de los grupos nobiliarios que se agitan ante la ascensión de un advenedizo como Godoy, y sus acciones no tienen otro norte que molestar a este, en este sentido creo que cobra su verdadera dimensión el hecho de que el hijo de la condesa Benavente el futuro Conde de Montijo traduzca obras revolucionarias $\left(^{5}\right)$.

Pero entonces ¿como en pocos años esta ideología afín a medios tan rancios del Antiguo Régimen se va a convertir en un peligroso ingrediente de la ideología revolucionaria? Esta es una de mas muchas contradicciones de aquélla época. El hecho decisivo que cambia el sentido del jansenismo español es sin duda la aprobación en Francia de la Constitución civil del clero.

Hasta entonces las personas tratadas de jansenistas habían sido obispos, condesas, pero de ahora en adelante son revolucionarios.

¿Qué ocurrió para que el jansenismo adquiriera estas connotaciones? Me parece claro que fue la intervención decisiva en las Cortes de Cádiz a favor del liberalismo de un pequeño pero influyente grupo clerical que fué tachado inmediatamente por los absolutistas de jansenista, y contra los cuales se desencadenó una sañuda persecución política durante las represiones absolutistas de 1814 y 1823.

Pero ¿cuales eran los aspectos mas destacados de esta ideología jansenista? que tanto alarmó a sus enemigos por su nuevo caracter revolucionário? Hay alguna diferencia entre esta generación de jansenistas y las anteriores? Vamos a ver cuales son las principales características que se atribuyen. La dirección del grupo o partido se atribuye a eclesiásticos aunque también haya seglares y sobre todo se destaca la influencia de aquellos sobre «cierta clase media», la cual les sigue a pesar de su ignorancia por el señuelo de empelos y dignidades.

(5) Existe una biografía de la Condesa de P. Demerson. M. ${ }^{a}$ Francisca Portocarrero, condesa de Montijo. Una figura de la Ilustración, Madrid, 1975. He aquí una anécdota que dió fama al Obispo Antonio Palafox, del circulo de la condesa uen uno de estos ratos se le acercó una persona decentemente vestida y la pidió limosna! Como pedís limosna exclamó el S. Palafox, siendo joven y robusto! Desde este momento comienza a trabajar en esta obra y podrá comer sin ruborizarse. Señor, mi educación me hace imposible un trabajo como este. Pues sea sobrestante con diez diarios. Señor, soy noble y mi clase no permite. Pues hijo si eres noble yo soy Grande de España de primera clase y no me abochorno de ayudar a estos trabajadores a voltear un sillar, ni a acercarles las herramientas, ni de quitar siguio, cuando estorba» en Muñoz y Soliva, Noticias de todos los Ilmos. Señores que han regido la Diócesis de Cuenca...., Cuenca, 1860, p. 474. 


\section{Jansenismo en España}

Desde el punto de vista estrictamente eclesiástico son acusados sobre todo de denigrar la autoridad pontificia. Punto fundamental cuando tanto las Cortes de Cádiz como las del trienio pretendieron llevar a cabo una auténtica reforma eclesiástica, que naturalmente solo se podía hacer a costa de la autoridad papal. Este afán de reformar la Iglesia por parte de la autoridad se prolongará en un regalismo cada vez mas trasnochado en el partido progresista en las poucas ocasiones que tuvo el poder en el reinado de Isabel II.

\section{La influencia de la Constitución civil del clero}

Sin embargo, los jansenistas españoles una vez tomado conocimiento de los debates en las Constituyentes de Francia de las discusiones sobre esta reorganización de la Iglesia de Francia conocida con el nombre de Constitución civil del clero y votada el 12 de julio de 1790 y sancionada por el rey Luis XVI el 24 de agosto siguiente. $\mathrm{Y}$ aunque condenada inicialmente por Pio VI por dos Breves de 1791 sería finalmente aceptada por la Santa Sede, quedaron muy bien impresionados por ella $\left(^{(}\right)$.

La Constitución civil del clero buscaba la regeneración de la Iglesia de Francia por medio de la vuelta a la disciplina de la Iglesia primitiva. Para ello se trataba de simplificar y unificar la organización de la Iglesia en Francia, y sobre todo buscaba crear una iglesia nacional dependiente lo menos posible de Roma, objetivo por otra parte pretendido por la Iglesia de Francia desde hacia siglos.

Concluían en la ideología que sostenia a los defensores de la Constitución ciertas corrientes que venían corriendo paralelas y que ahora confluían, había por un lado un laicismo de raíz protestante que hacía recular la noción ortodoxa de sacerdocio. Un regalismo extremo que destruía la jurisdición eclesiástica. Un episcopalismo galicano que atacaba la primacía

(8) «J'ai vu en Espagne des curés aussi virtués regarder les plus beaux-discours de membres de l'assemblée constituante, comme les résultats de la grâce qui leur était inspirée du Très-Haut en récompense des réformes salutaires qu'ils allaient introduire dans l'Eglise Anglaise» (sic) en "Quelques réflesions sur le projet de résolution sur les prétres», La tribune politique, n..$^{\circ}$, 1797. Le agradezco esta cita de Marchena sinceramente al profesor Fuentes Aragones que amablemente me la ha facilitado. Aunque el Abate Marchena no se refiere a nadie en concreto creemos que una figura en la que podemos ver muy bien representado este sector del clero español, desde luego minoritario, es el famoso clérigo sevillano Blanco White. 
del Papa, y el jansenismo extremo que igualaba el sacerdocio presbiteral y episcopal.

Nada de esto podía asombrar a la Iglesia galicana, no es de extrañar por eso que un «robin» constituyente Durand de Maillane defendiera la nueva Constitución recordando

"Il est assez étonnant que, sur la fin du dernier siècle (se refiere a la asamblea de 1682), les evêques français ont seuls interprété, sans l'intervention du Pape, le voeu de l'église gallicane sur des objets pour le moins aussi intéressants que ceux dont il s'agit aujourd'hui... Mas la chance est bien differente! Alors il s'agissait de nos évêques contre le Pape, et à présent il s'ágit du Pape et dieux contre la Nation.... Alors ils rafaissaient le Pape pour s'élever eux mémes, et maintenant ils apellent le Pape à leur secours.... Alors ils sommettaient le Pape aux canons des Conciles, et maintenant ils se sommettent eux-mêmes à la seule voix du Pape: mais c'est parce que son langage est le leur» (7).

La influencia de esta Constitución civil del clero en España fué notable dentro de los circulos eclesiásticos calificados como jansenistas y esto se mostraría de forma palpable cuando se convocan las Cortes en 1810 y luego en 1820 . Destacados reformistas, como por ejemplo Villanueva son directos deudores de la Constitución civil del clero, a la que sigue en sus propuestas tanto en el fondo como en la forma $\left.{ }^{8}\right)$. Hoy puede llamarnos la atención este afán de un diputado por ocuparse de días festivos, diezmos y bienes, reforma del clero regular y secular, regulación de monasterios, etc. Pero si tenemos en cuenta la presencia tan importante de la Iglesia en la sociedad española de entonces, esto nos parecerá más natural.

En la medida en que la Iglesia salga de la crisis del Antiguo Régimen despojada de tanto elemento superfluo y encuentra una estructura mas sencilla y lineal este pensamiento irá desapareciendo aunque siempre quedarán en el liberalismo español resabios regalistas, consecuencia del retraso de la sociedad española por secularizarse debidamente $\left(^{9}\right)$.

(7) Pierre Toussaint Durand de Maillane, Histoire apologétique du Comité eclesiastique de l'Assemblée Nationale, París, 1791, I, pp. 228-229.

(8) J. S. Laboa, Doctrina canónica del doctor Villanueva. Su actuación en el conflicto entre la Santa Sede y el Gobierno de España (1820-1823), Vitoria, 1957.

(9) El conocido historiador Roger Aubert considera que un liberalismo católico en España era imposible por razones temperamentales 


\section{Jansenismo en España}

\section{El jansenismo en el trienio Constitucional}

La influencia jansenista ya sin connotaciones políticas sin embargo impregna la sociedad entera, y esta influencia con su cortejo de prohibiciones persistirá hasta el siglo XIX, de forma que se puede decir que una de las características de la moral de nuestros días es el fín del jansenismo y del moralismo burgués. El odio del cuerpo, el horror de todo esto que puede ofender el «buen gusto», la gran invención burguesa, tiene su origen en la moral jansenista $\left({ }^{10}\right)$.

La cuestión se centra en el afán del liberalismo español de intervenir en asuntos estrictamente eclesiásticos, pero esto no es consecuencia de la ideología jansenista, sino más bien de la excesiva presencia de la Iglesia y de los eclesiásticos en la sociedad española que hoy quizás sea difícil entender. Pero entonces con una Iglesia tan numerosa y tan poderosa económicamente, que además en su gran mayoría se resiste a aceptar el cambio de régimen político, se hacía absolutamente necesaria una acción política sobre ella, que además encuentra su soporte en las doctrinas regalistas tradicionales. Tras la muerte de Fernando VII el jansenismo perderá protagonismo e incluso se deja de utilizar el termino tanto por sus partidarios como por sus enemigos, la razón está en que en Europa ya se ha elaborado un catolicismo liberal que supera ampliamente el jansenismo, y en España no se configura ese catolicismo liberal por la necesidad que tiene el liberalismo español por su debilidad de pactar con la Iglesia Católica lo que también deja sin lugar a la ideología jansenista.

«Ou a quelque hésitation à parler du liberalisme catholique en Espagne. Le tempérament espagnol, si fier, si entier, n'est guére compatible avec la songelese nécessaire à un rapprochement entre les principes de 1789 et la pensée catholique traditionelle. Il existe en Espagne una tension entre deux partis extrémes, aussi intransigeants l'un que l'autre, liberaux radicaux anticatholiques et réactionnaires cléricaux 'antimodernes' en le liberalisme religieux au XIX siècle», en $X$ Congresso Internazionale di Scienze Storiche, Relazioni V, Florencia, Sansoni, 1955 y también Fliche Martin, Histoire de l'Eglise, T. XXI, p. 181.

(10) Llama la atención que por ejemplo en toda la polémica sobre el teatro español, un personaje como Leandro Fernández de Moratín utilice como argumento contra el teatro de los siglos XVI y XVII un criterio de pudibundez y rigorismo moral sorprendente. Hasta el punto de que al comentar la supresión de los autos sacramentales por Carlos III, la justifica por la "irreligiosa y sacrílega algazara" a que daban lugar. Ciertamente resulta llamativa esta preocupación de Moratín por la religión, vid. Obras de $D$. Nicolas y $D$. Leandro $F$. de Moratín, B.A.E., II, pp. 307-325, sobre todo 316. 
Esto explica que cuando se produce la reacción absolutista de 1814 y luego la de 1823 los jansenistas aparezcan totalmente identificados con el nuevo régimen político liberal que se ha acabado de derrocar y sufran las consecuencias de la represión.

Es importante en este momento decisivo tratar de comprender qué se entendía por jansenista, por lo menos desde el punto de vista de sus enemigos los absolutistas, siguiendo a un fiel testigo de aquellos hechos ( $\left.{ }^{11}\right)$.

En primer lugar, se les considera un fenómeno directamente relacionado con la Ilustración del siglo XVIII y así se manifiesta claramente: «Desde la Revolución de Francia, Jansenistas y Francmasones, Jacobinos y Ateistas, son palabras idénticas» $\left({ }^{12}\right)$.

Bajo el epígrafe Descripción del Jansenismo y Jansenistas modernos $\left({ }^{13}\right)$, establece claramente una distinctión entre el jansenismo del siglo XVIII y el que aparece ahora ligado a la Kevolución, «L's un hecho evidente que la grande Revolución francesa de 1789 y siguientes se consumó por la unión o liga de los impíos con los Jansenistas del Reynos $\left({ }^{\mathbf{1 4}}\right)$.

(11) «Segundo aviso al verdadero y legítimo pueblo español sobre la conducta de los malos eclesiásticos conocidos con el nombre de jansenistas y males gravísimos que han causado a la España. Se descifran sus misterios de iniquidad: se ponen de manifiesto sus errores, y castigos que merecen. Por un Español deseoso del bien de sus conci dadanos», Madrid Imprenta que fué de García, por su Regente D. Manuel Pita de la Vega, 1823.

«Así piensan, así obran los hereges de Europa: y si su crítica se hubiera de ejercer sobre el procedimiento de las Cortes de España, sería la de la aprobación, si no se ingieren como legisladores en los n€gocios eclesiásticos: y la de una severidad justa, si vieren desconocido un principio, que nadie hasta ahora se atrevió a negar sino la Asamblea Nacional de Francia, compuesta en gran parte de impíos seculares y de Jansenistas eclesiásticos, como lo llora Pio VI en sus bulas dirigidas a aquel desgraciado Reyno».

(12) "Así como entre los seculares las luces del siglo, o la falsa filosofía ha producido los monstruos llamados Masones, Deistas, Materialistas, Constitucionales, o negros, los cuales aunque divididos en varias sectas, todos convienen en llamar Soberano al pueblo para escravizarlo, y déspotas a los Reyes para mandar ellos con un cetro de hierro: Así también entre los eclesiásticos, a quienos no dejan de seguir algunos seculares, las luces falsas de una ciencia vana, o cierta erudición aparente propia del partido produce otros monstruos no menos malignos que los primeros a los cuales llamamos comunmente Jansenistas....", Loc. cit.

(13) Idem.

(14) Idem. Isidoro de Villapadierna, en «El jansenismo español y las Cortes de Cádiz», en Nuove Richerche Storiche sul Giansenismo, Roma, Universidad Gregoriana, 1954. 
El autor recuerda la grave crisis provocada por Urquijo ya en 1799. Es el punto culminante de la influencia jansenista este intento de Urquijo de obligar al Consejo de Castilla a autorizar la impresión de las obras del P. Antonio Pereyra y Genaro Castari en lo que fracasó, pero en cambio si consiguió sacar adelante el decreto de 5 de septiembre de 1799 y la difusión fraudulenta de Febronio y Pereyra $\left({ }^{15}\right)$.

Estas son las fuentes además de Eybel y otros parecidos y el desprecio de las falsas decretales, «que es la sal que sazona todos sus discursos académicos», del jansenismo y del regalismo.

$\mathrm{El}$ autor considera que los jansenistas españoles disimulan sus verdaderas ideas por eso hay que descubrirlos y propone para ello el criterio a seguir:

\begin{abstract}
«Ahora bien: cuando veais alguno, sea clérigo o fraile, canónico u obispo que habla mal del Papa, que desprecia sus bulas y decretos, que declama contra los usos y costumbres de la Iglesia, lo que por otro nombre se llama disciplina actual y se lamenta de que no se restablezca la disciplina de los siglos primitivos: por notoria probidad que aparente, aunque lleve una vida al parecer de los hombres santa y recogida, que su exterior sea humilde y modesta, su conducta arreglada, y su fama de sabio $e$ instruído, desconfiad de él al momento, latet auguis in herba, es muy probable, mucho mucho, que bajo aquella vestidura de oveja está escondido un lobo feroz, un fino jansenista" ( $\left.{ }^{16}\right)$.
\end{abstract}

Señala la importancia y la influencia que tuvo en España la Constitución civil del clero y cómo el mismo camino llevábamos en las Cortes de Cádiz con los Decretos sobre Regulares,

(15) El teólogo portugués Pereyra tuvo ya una influencia notable en España cuando publicó sus obras en Portugal y prueba de ello fué la polémica que se desarrollo que dió lugar a su escrito titulado: Respuesta apologética de Antonio Pereyra, Presbitero de la Congregación del Oratorio de Lisboa al padre Gabriel Galindo, Theologo en Madrid o a la Censura que este hizo de su Tentativa Theologica, impresa en Lisboa, sobre el poder de los Obispos en tiempo de Rotura con la Corte de Roma, 1786. El interés por su obra se renovó en los años finales de siglo.

El libro de Castari se titulaba, El espiritu de la jurisdición eclesiástica sobre la Consagración de los Obispos. Tanto Castari como Pereyra fueron traducidos por Caseda y Muro tal como consta en su amplio dosier conservado en el AHN (Estado 3014). Godoy acusó a Llorente de ser el traductor de Pereyra, quien naturalmente lo negó.

(16) «Su objetivo es vilipendiar a la cabeza visible de la Iglesia y despreciar sus bulas y decretos para vivir sin freno, sin sujeción y dominar al clero». Ibidem. 
inmunidad eclesiástica, vacantes de obispados, etc. $\left({ }^{17}\right)$. Recuerda otros significativos datos

"Así don Juan Antonio Llorente e su horrible proyecto de una Constitución religiosa. Ved aquí patente el verdadero significado de la palabra Ilustración e ilustrados, despreciar al Papa, y no hacer caso de sus excomuniones» (18).

Es muy significativo las consideraciones que hace sobre la influência del jansenismo entre los jóvens, las mujeres y cierta clase media que coincidem con las de otros autores $\left({ }^{19}\right)$. Así como su descaliticación como patriotas $\left({ }^{20}\right)$.

\section{(17) Ibidem.}

(18) Llorente publicó en Francia a finales de 1819, por consiguiente en vísperas del pronunciamiento de Riego y de la nueva apertura de las Cortes Liberaies una obra titulada Discursos sobre una constitución religiosa, considerada como parte de la civil nacional, en Stahl, Paris. Liorente que fue siempre un cobarde no se atrevió a presentar la obra cumo suya y acudió al expediente de presentarse solo como editor de la obra que había caído en sus manos. La estratagema era inútil entre otras cosas porque no se trataba mas que de una refundición de una obra anterior suya titulada Petit catéchisme sur les concordats. Gerard Dufour ve un cierto sentido a que los Discursos sobre una Constitución religiosa, se la atribuyese a un "americano» porque Llorente ponía todas sus esperanzas en la evolución de la situación política en Amérıca para ver si se aplicaban allí sus teorías religiosas, por eso considera la independencia de América desde el punto de vista de la disciplina eclesiástica, ya que podía permitir lo que de momento parecía imposible en Europa, la aplicación de la constitución civil del clero. Esta claro que a él poco le importaba el régimen político: había apoyado las reformas de Urquijo, luego al Rey José Bonaparte y ahora al régimen constitucional español, vid. Gerard Dufour, Juan Antonio Llorente en France (1813-1822), Droz, 1982.

(19) "el bien de la religión, su mayor pureza, la disciplina exacta de los siglos primitivos, la reforma de los abusos, el destierro de la superstición $\mathrm{y}$ fanatismo son las dulces voces con que alucinan los Jansenistas a las mujeres sencillas, y a la multitud de gentes incautas...." Loc. cit.

"Y ve aquí otro carácter, en que convienen los negros Masones y negros Jansenistas, pues unos y otros echan manos de cierta clase media que sin saber lo que es Constitución ni Jansenismo sirven para aumentar el número y son atraídos con el cebo de los empleos los primeros y el renombre de sabios y algunas dignidades los segundos". Loc. cit. Ctro texto interesante es el titulado: Segunda Advertencia reverente a su Majestad y a los señores Diputados de las Cortes sobre materias eclesiasticas, bienes y rentas de la Iglesia, y sobre regulares, Madrid, Imprenta de Vega y Compañia, 1820.

Es llamativa la insistencia de que los jefes jansenistas tienen sus mayores partidarios en los jóvenes y las muieres («jóvenes infatuados con sus estudios jansenísticos o unas mujercillas mediobeatas y mediobachilleras ilustradas a estilo de sus maestros»), Dice el autor de Segundo Aviso...." Vid. A. González Palencia, Noticias bibliograficas 


\section{Jansenismo en España}

de Hervás, en Eruditos y libreros del siglo XVIII, CSIC, Madrid, 9148. Hervás y Panduro uno de los mas famosos jesuítas refugiados en Italia tras su expulsión de España escribió entre otras obras Historia de la vida del hombre en 13 tomos, el VII de ellos fué censurado por Joaquín Lorenzo Villanueva, el cual, en el prólogo de su obra Catecismo ael Estado, según los principios de la religión, publicado en Madrid en 1793 y en donde atacaba la Revolución Francesa, censura varias proposiciones de la obra de Hervás a la cual esta respondió, recogemos aquí algunas frases significativas de esta respuesta para el asunto á que nos referimos "Yo hablo claramente, no solo de la Biblia, mas también de los libros de los oficios divinos, de los misales, etc. que los acólitos y principalmente los jansenistas proponen en lengua vulgar aún a las mujeres para que disputen de teología como damas de la gracia y puedan celebrar y entender la misa como meras sacerdotisas; y nuestro autor sobre este punto, nada dice sino llamarme libertino; mas él no puede negar esta practica de crearse sacerdotisas por los jansenistas, la cual consta por confesión de una de sus damas de la gracia....», p. 277.

(20) «Parecen españoles y lo son de nacimiento, mas no tiene la España peores enemigos, parecen católicos y realmente estan bautizados, pero son cismáticos, son algunos de ellos herejes, y otros también apóstatas». 